\title{
HispanismeS
}

Revue de la Société des Hispanistes Français

\section{La ciudad como interfaz : creación artística, esfera pública y tecnologías de la comunicación}

La ville comme interface : création artistique, sphère publique et technologies de la communication

The city as an interface: artistic creation, public sphere and communication technologies

\section{Diego Díaz y Clara Boj}

\section{OpenEdition}

\section{Journals}

Edición electrónica

URL: https://journals.openedition.org/hispanismes/428

DOI: 10.4000/hispanismes.428

ISSN: 2270-0765

\section{Editor}

Société des Hispanistes Français

\section{Referencia electrónica}

Diego Díaz y Clara Boj, «La ciudad como interfaz : creación artística, esfera pública y tecnologías de la comunicación», Hispanismes [En línea], 14 | 2019, Publicado el 01 octubre 2019, consultado el 31 agosto 2021. URL: http://journals.openedition.org/hispanismes/428 ; DOI: https://doi.org/10.4000/ hispanismes. 428

Este documento fue generado automáticamente el 31 agosto 2021.

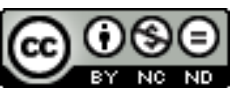

Les contenus de cette revue sont mis à disposition selon les termes de la Licence Creative Commons Attribution - Pas d'Utilisation Commerciale - Pas de Modification 4.0 International. 


\section{La ciudad como interfaz : creación artística, esfera pública y tecnologías de la comunicación}

La ville comme interface : création artistique, sphère publique et technologies de la communication

The city as an interface: artistic creation, public sphere and communication technologies

Diego Díaz y Clara Boj

\section{Introducción}

1 Desde las ciencias de la computación se entiende el término interfaz como un espacio de comunicación entre dos agentes de distinta naturaleza, donde gracias a un protocolo compartido se establece una comunicación entre ellos, un nuevo tipo de espacio relacional, según Branden Hookway ${ }^{1}$, y también un lugar donde se representa la cultura contemporánea, tal y como sostiene Steven Johnson ${ }^{2}$. En la teoría urbana, el término interfaz se refiere normalmente a la manera en que los ciudadanos se adaptan o intentan adaptarse a los ritmos colectivos, prácticas y lógicas de las comunidades urbanas de las que forman parte. Esta acepción ha sido utilizada entre otros por Manuel Castells.

Las ciudades siempre han sido sistemas de comunicación basados en la interfaz entre individuos e identidades colectivas y representaciones sociales compartidas. [...] Lo que hace a las ciudades productoras de sociabilidad es su habilidad para organizar su interfaz en formas, ritmos, experiencias colectivas y percepciones de comunicación ${ }^{3}$.

2 Esta ciudad entendida como una interfaz se nos muestra como espacios-mecanismos donde la esfera pública urbana se desarrolla, donde tienen lugar los roles sociales, el encuentro, la confrontación entre ciudadanos y la creación de públicos urbanos. 
3 La esfera pública urbana no es solamente un escenario neutral en el que los ciudadanos actúan como tales sino que también forman parte activa del mismo. Repertorios culturales específicos están ligados a lugares específicos y estos lugares conforman el escenario para las interacciones que se consideran apropiadas en estos lugares. Las prácticas sociales, culturales, económicas, tradiciones y estructuras de poder se manifiestan en estructuras urbanas físicas tanto como en los protocolos que regulan los emplazamientos urbanos concretos. Cuando un ciudadano llega a un espacio se familiariza con la lógica específica y los ritmos de este sistema social, puede tratar de ajustar su vida a estas lógicas o tratar de cambiarlas, puede identificarse con los protocolos, los ritmos y las prácticas o tratar de resistirse y re-formularlas. La ciudad actúa como una interfaz: prácticas y valores colectivos se insertan físicamente en la ciudad, en sus protocolos sociales y espaciales. Cuando estas prácticas colectivas cambian, la ciudad cambia con ellas ${ }^{4}$.

4 Con la llegada de las tecnologías digitales a la vida urbana cotidiana, la ciudad como interfaz ya no es una metáfora, ya no podemos hablar solamente de la esfera pública física como lugar de encuentro y relación. Las redes sociales y las actualizaciones de estado comienzan a actuar también como interacciones sociales en la que los ciudadanos llevan a cabo su vida diaria. De una forma similar los motores de búsqueda, los dispositivos GPS o los teléfonos inteligentes rediseñan nuestras prácticas cotidianas en la ciudad. Los valores sociales e ideales urbanos específicos se codifican en líneas de código que construyen los protocolos que convierten estas interfaces. Todos estos factores configuran la manera en la que transcurre nuestra vida social y con quien interaccionamos.

5 Un conjunto creciente de tecnologías y servicios está afectando a la manera en que se configura la esfera pública, es difícil utilizar una sola etiqueta para definir estas tecnologías, normalmente se definen desde disciplinas tan diversas como la computación ubicua, los locative media, los ambientes inteligentes o el Internet de las cosas, desde la ciudad sensible a la computación urbana. Ninguna de estas tecnologías tiene un solo punto de partida en su desarrollo, algunas de ellas se han desarrollado por agencias gubernamentales que quieren poner orden y controlar el espacio urbano. Otras se han llevado al mercado por compañías de telecomunicaciones movidas por el beneficio económico proveyendo a sus clientes con servicios personalizados. En ocasiones trabajadores sociales usan estas tecnologías para favorecer entendimiento entre diferentes grupos culturales. Desde el arte se trabaja con estas tecnologías para criticar su papel en la promoción de una sociedad basada en el consumo o hablar de su papel en una sociedad de control. Por otro lado los usuarios finales de las tecnologías a menudo se apropian de ellas de manera diferente a las que fueron diseñada originalmente por el mercado. Lo que todas estas tecnologías urbanas tienen en común es que ya no se conciben como creadoras de una realidad externa llamada "ciberespacio" poblada por "identidades nómadas" organizadas en "comunidades virtuales"; por el contrario estas tecnologías se centran en su capacidad de localización para añadir aquí y ahora específicos, entendidos como una suerte de nuevas experiencias geolocalizadas, creando ciudades híbridas cuyas experiencias se construyen tanto por entornos físicos como por contenidos digitales que surgen en estas situaciones físicas desde distintas tecnologías.

6 Según Martijn De Waal ${ }^{5}$ podemos clasificar en dos grandes grupos estas tecnologías. El primer grupo serían las tecnologías que tienen la capacidad de ser utilizadas como 
herramientas de escritura o marcadores de experiencia: muchas de las tecnologías actuales permiten a los usuarios escribir literalmente sus experiencias en la ciudad. Los ciudadanos pueden dejar memorias $\mathrm{u}$ otras señales $\mathrm{y}$ vincularlas a lugares específicos (geotag); los visitantes a estos lugares pueden acceder a este contenido, del mismo modo los ciudadanos pueden utilizar la actualización de estado de las redes sociales para describir donde están y que están haciendo. Estas prácticas se han venido a llamar "desdoblamiento" de la esfera pública urbana. Las plataformas físicas de las calles son aumentadas con bases de datos en las que se almacenan registros o representaciones de las actuaciones sociales que tienen lugar allí. Esto quiere decir que el público de estas acciones ya no es solamente el que tiene una presencia física sino también los que están ausentes.

7 El segundo tipo de tecnologías es el de dispositivos territoriales, con esto Waal se refiere a herramientas que intervienen en la experiencia de un espacio en particular, desde la perspectiva de un ciudadano el teléfono móvil es una herramienta potente que nos permite cambiar la experiencia del espacio. Por ejemplo cuando un ciudadano está en la ciudad siempre puede acceder a la red de amigos a través del teléfono móvil, también puede utilizar aplicaciones específicas para seleccionar lugares basados en sus preferencias personales. Esta capacidad de crear territorio funciona conjuntamente con la capacidad de escritura, por ejemplo : los rastros que una persona deja en su red social se pueden reconstruir en un perfil personal, este perfil se puede utilizar con un algoritmo especial para filtrar la ciudad, donde una aplicación del teléfono, por ejemplo, puede recomendar o evitar que visite un lugar específico.

8 En su conjunto las capacidades de los medios digitales para ser utilizados como marcadores de experiencia o dispositivos de territorio cambian el modo en que la esfera pública urbana funciona como interfaz, añade capas a la esfera pública urbana y, por tanto, amplía la presencia al incluir a las personas que no se encuentran físicamente en el espacio urbano.

Las nuevas tecnologías también cambian la manera en la que se organizan los espacios físicos. Los espacios urbanos se convierten en interactivos y reaccionan a la presencia de los ciudadanos. Los ciudadanos pueden reprogramar la experiencia de un lugar específico con la ayuda de su teléfono móvil. También pueden utilizar estas tecnologías para "filtrar" la ciudad y generar recorridos basados en su criterio específico. Todos estos procesos se regulan a través de protocolos con las que están programadas las tecnologías. Pero ¿a qué ideal urbano sirven estos protocolos? ¿Qué códigos culturales se codifican en el código de computación? ¿Cómo las tecnologías digitales permiten a los ciudadanos, en el contexto de la ciudad, representarse a sí mismo y formar parte de la esfera pública? ¿De qué manera estas tecnologías median la forma en la que los ciudadanos se relacionan?

En este artículo vamos a intentar responder a estas y otras preguntas a través de nuestra práctica artística reciente. Para ello, hemos clasificado en distintas categorías algunas de las investigaciones que hemos realizado desde el año dos mil. Las investigaciones aquí presentadas responden a la necesidad de analizar críticamente las transformaciones sociales producidas en la ciudad por la constante aparición de nuevas tecnologías y servicios. Entendemos estas investigaciones desde la práctica artística, enmarcada en el contexto del arte contemporáneo y concretadas como obras y/o dispositivos de pensamiento, realizadas con el objetivo de analizar y ejercer una reflexión crítica sobre la evolución de la ciudad y del espacio público. 


\section{Ciudad sensible - ciudad reactiva}

La miniaturización de las tecnologías y el desarrollo de las redes de comunicación ha promovido la expansión de la computación ubicua ${ }^{6}$, basada en la integración de los sistemas informáticos en el entorno de las personas de forma que los ordenadores no se perciban como objetos diferenciados. También definida como inteligencia ambiental ${ }^{7}$, la computación ubicua integra dispositivos alrededor de escenarios donde se encuentra el ser humano de modo que éste puede interactuar de manera natural con los dispositivos y realizar cualquier tarea diaria de manera completamente transparente con respecto a su ordenador, sin apenas percibirlo. Los sistemas de computación ubicua comparten el hecho de ser pequeños, fácilmente integrables en el contexto urbano, robustos, con gran capacidad para el procesamiento de red y distribuidos en todas las escalas que comprende el día a día actual.

Un ambiente inteligente puede adaptarse, por ejemplo, a la evolución ambiental del día para ajustar sistemas de iluminación y calefacción, variando la temperatura y condiciones de una vivienda o edificio de manera continua e imperceptible. Una expansión exponencial de la computación ubicua nos lleva a entender la ciudad y el entorno urbano como un espacio en el que las tecnologías integradas son sensibles a los cambios y reaccionan a los mismos, transformándose en función de las necesidades de los ciudadanos, recopilando información ambiental para transformar las condiciones espaciales del entorno y adaptarlo a las especificidades del momento.

13 La ciudad sensible es capaz de ver, oír y en definitiva sentir los distintos aspectos ambientales de carácter natural y humano y provocar cambios en respuesta a estos estados reaccionando a las influencias del contexto.

\subsection{A Central Axis}

14 Bajo el paradigma de la ciudad sensible y reactiva desarrollamos en el año 2003 la investigación A Central Axis ${ }^{8}$, formulada como un agente autónomo que representa a tiempo real las actividades que suceden en los entornos físicos y virtuales de relación social. Este proyecto analiza los espacios de comunicación social, concretamente cómo la plaza pública tradicional ha dejado de ser el espacio por excelencia de encuentro entre los ciudadanos, para pasar a ser Internet y los entornos virtuales de relación social. A Central Axis define un nuevo espacio multiuso de hibridación de experiencias de vida físicas y virtuales marcadas por las relaciones humanas. Podemos entenderlo como un espacio público que respira al ritmo de la actividad humana fuera de parámetros espacio temporales. 
Fig. 1 Imagen de A Central Axis en el Singapore Art Musem

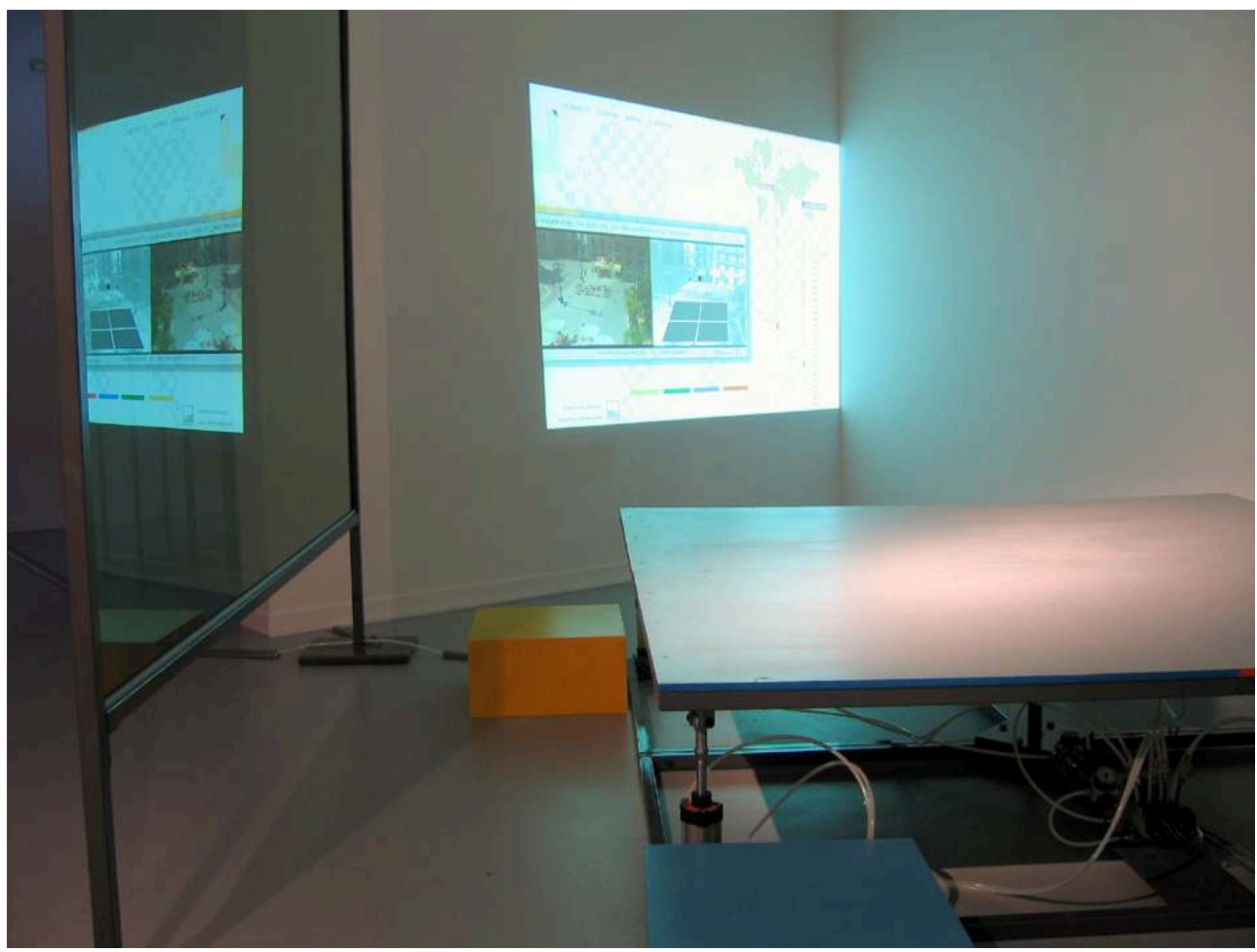

Clara Boj \& Diego Díaz, 2003

El proyecto de investigación se concretó en una instalación site-specific que fue mostrada en el Singapore Art Museum en el que durante un año los visitantes pudieron sentir la presencia remota de las personas al cruzar el espacio físico de la plaza de la Virgen en Valencia y en un espacio virtual de relación social, un chat de Internet. En el museo de Singapur creamos una plataforma pisable de cuatro metros cuadrados de superficie que se nos muestra como un elemento vivo, que respira, gira y se torsiona. Parece como si el suelo pasara de ser un elemento inorgánico a ser un ente sensible. En realidad las inclinaciones arrítmicas de la estructura están determinadas por los movimientos de las personas al pasar por la Plaza de la Virgen en Valencia, España a $10.000 \mathrm{~km}$ de distancia. Paralelamente la actividad de los espacios virtuales de relación social están representados en la instalación gracias a una video proyección sobre superficie transparente utilizando técnicas para integrar la realidad aumentada espacial, tal y como exponen Bimber y Raskar'. Esta proyección nos muestra los seudónimos de las personas que entran y salen de un canal IRC específico que reaccionan, por medio de un sistema de visión por ordenador, esquivando a los visitantes que se encuentren en ese momento en la sala, subidos a la plataforma. De esta forma el sistema tiene una doble interacción con los visitantes que se suben a la plataforma, por un lado juega con el intercambio de equilibrios gracias al movimiento físico de la plataforma y por el otro con una interacción visual de la video proyección. 
Fig. 2 Imagen de A Central Axis en el Singapore Art Musem

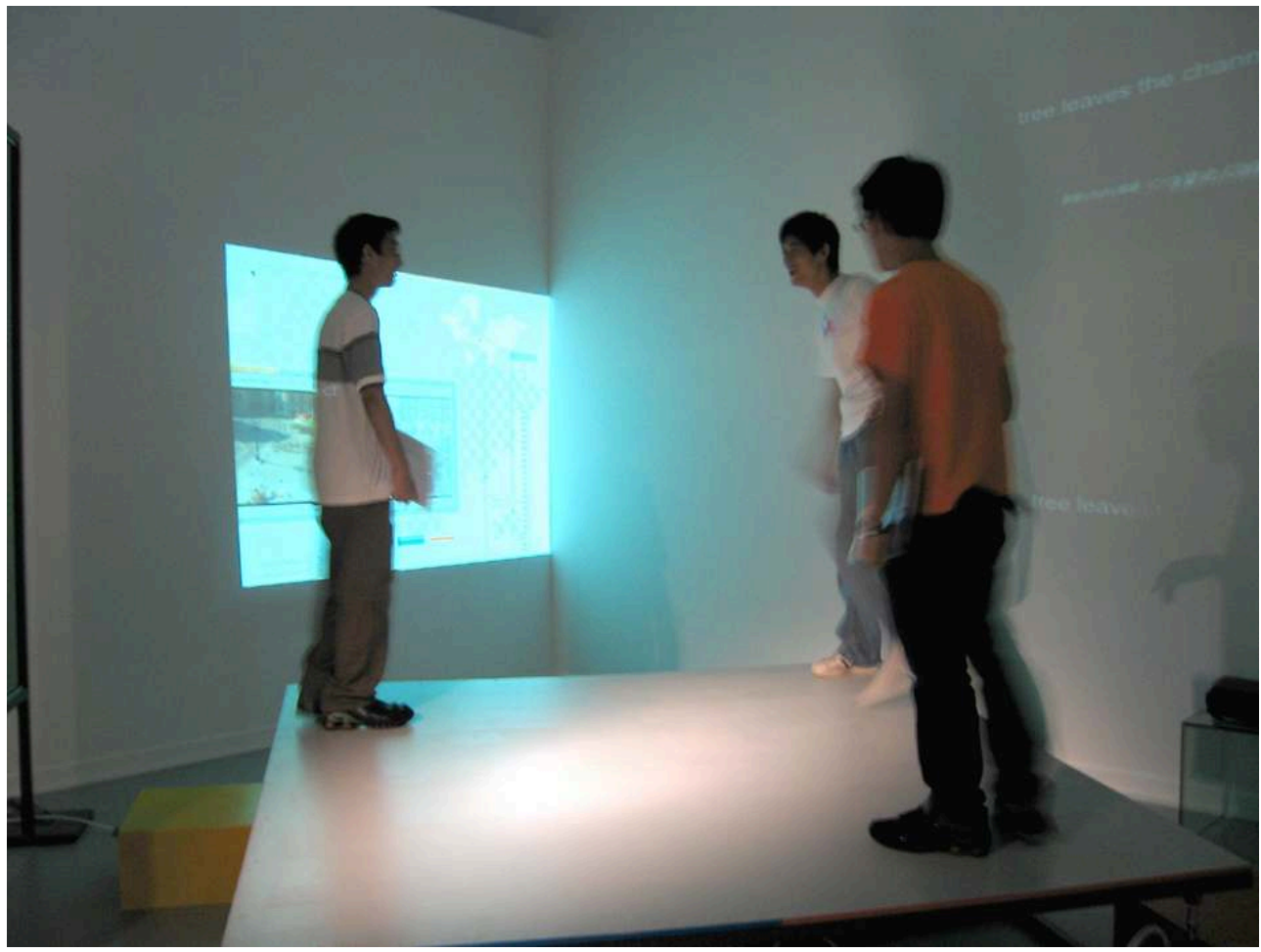

Clara Boj \& Diego Díaz, 2003.

La percepción que los visitantes de la instalación A Central Axis en Singapur obtendrán de la plaza de Valencia y del canal de chat IRC será moderada por la interfaz del dispositivo tecnológico mostrado en la instalación. A través de la muestra e interpretación de estos espacios, hemos agregado una nueva capa de significado que será recibida de manera diferente por cada visitante, quien luego, cuando camine por un espacio público o entre en una sala de chat, podrán incorporarlo a su experiencia personal. Mientras tanto, los transeúntes en Valencia, que desconocen que a través de su presencia en un espacio específico están participando en un proceso tecnológico que culmina en una exhibición en el museo de Singapur, experimentarán su paseo por la Plaza de la Virgen de una manera muy diferente a aquellos que son conscientes de lo que está sucediendo ${ }^{10}$. 
Fig. 3 Imagen del sistema de visión por ordenador de A Central Axis

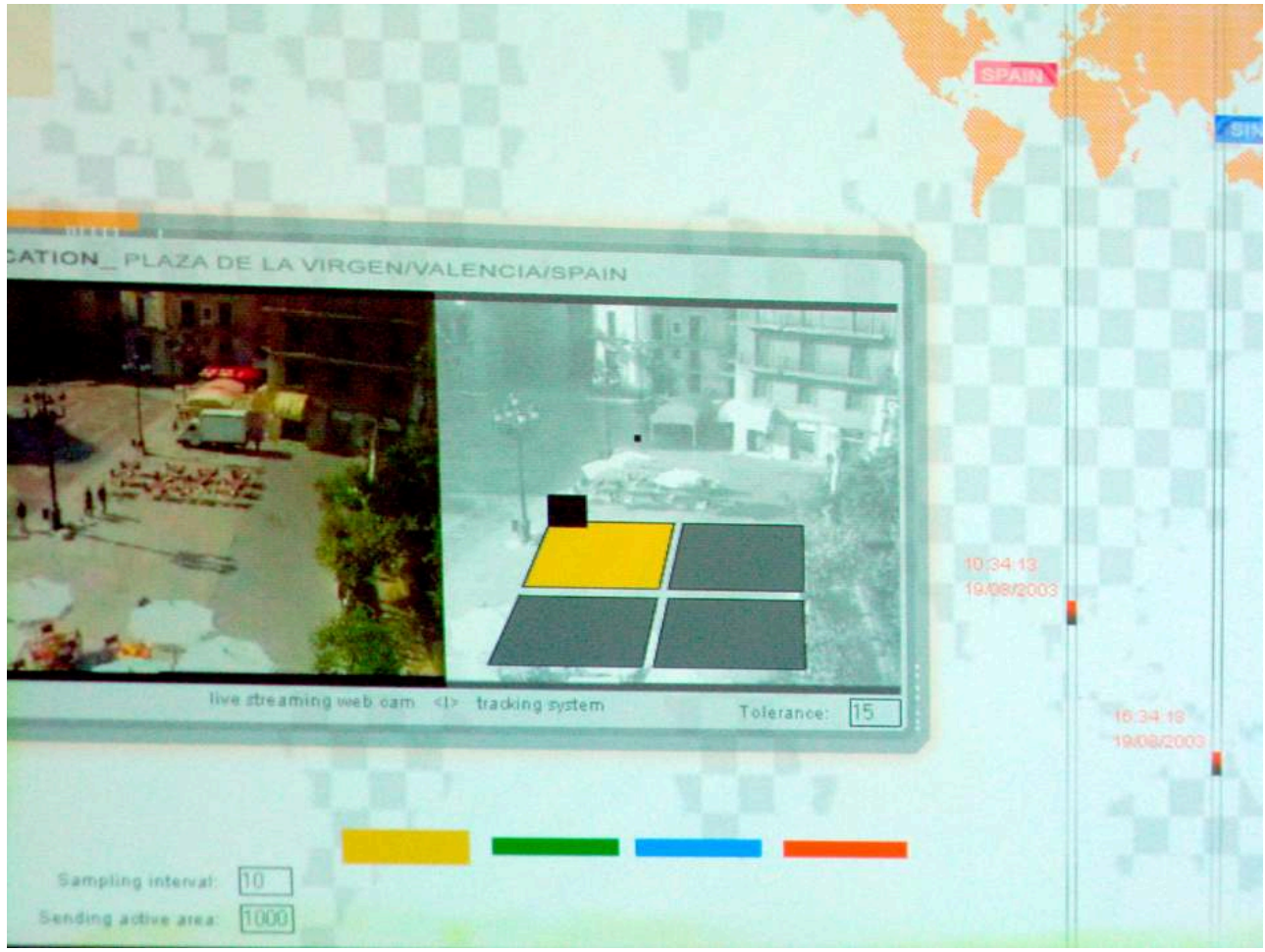

Clara Boj \& Diego Díaz, 2003

La presencia continua de tecnología a nuestro alrededor construye la ciudad sensible que agrega nuevas capas de significado a nuestros entornos cotidianos. Teléfonos móviles, ordenadores portátiles, cámaras web, dispositivos wearables, sensores, etc., aumentan las capacidades perceptivas del ser humano. Nuestras acciones cotidianas son continuamente registradas en el universo del Big Data donde nuestra construcción mental del mundo derivada de la percepción es ahora moderada por dispositivos tecnológicos.

\subsection{Zona de Recreo}

Paralelamente al desarrollo de A Central Axis realizamos el proyecto Zona de Recreo ${ }^{11}$, en esta investigación nuestro interés se centra en las áreas de juego infantil, y más concretamente en los parques públicos entendidos como espacios de juego y relación social, con dispositivos y estructuras diseñadas específicamente para ello. Inicialmente empezamos a analizar los usos de estos espacios : sus frecuencias de uso, la relación que los niños tienen con cada uno de los elementos del parque y el tipo de actividad y juego que realizan en ellos, el comportamiento que los acompañantes adultos tienen en estos lugares en un momento previo a la aparición de los teléfonos inteligentes, etc. Para realizar todas estas observaciones de campo registramos con una cámara de video $360^{\circ}$ varios parques de Valencia, este metraje de más de 50 horas de duración nos ayudó a analizar los aspectos anteriormente mencionados durante el momento de la grabación y también en su posterior visionado. Al tratarse de un sistema de registro novedoso (para el momento), una cámara de vídeo miniDV con una lente especial colocada en vertical sobre un trípode que apuntaba al cielo, los usuarios del parque no eran 
conscientes de que estaban siendo grabados por lo que su comportamiento no se vio afectado por nuestra presencia.

Tras el análisis minucioso de los parques infantiles, decidimos centrarnos en los balancines de muelle ya que estos elementos son los primeros en dejar de ser usados para los niños y niñas. Otros elementos como toboganes y sobre todo los columpios tienen un rango de edad de uso mayor, pero con nuestras observaciones pudimos comprobar que los balancines de muelle son los primeros en ser abandonados por los pequeños. Zona de Recreo nace de la transformación de uno de estos dispositivos con el objetivo de ampliar el rango de edad de uso del mismo incorporando los videojuegos como principal medio transformador. Consiste en una interfaz multiusuario que controla mundos virtuales en tiempo real, en cierta manera, es una especie de interfaz física de simulador de vuelo. La parte superior de la estructura tiene incrustada una pantalla táctil controlada por un sistema de sensores que nos permiten controlar las imágenes que aparecen en esta pantalla, de acuerdo con las variaciones de inclinación de la estructura.

Fig. 4 Imagen de Zona de Recreo

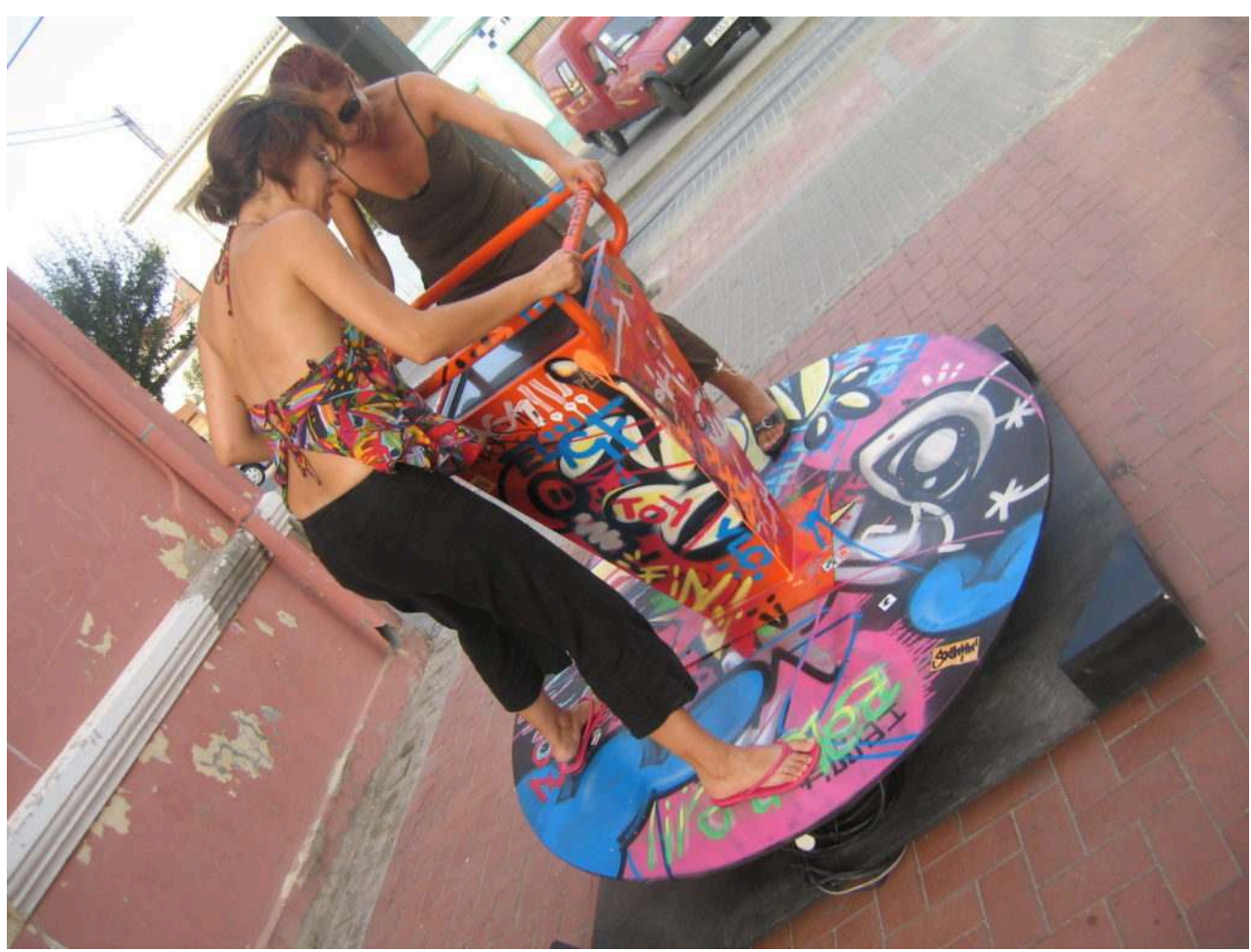

Clara Boj \& Diego Díaz, 2003.

El uso de este elemento y su trasformación nos permitió articular el marco discursivo en el que queríamos situar Zona de Recreo: el balancín nos remite a los espacios públicos y sus adaptaciones tecnológicas nos hablan de la revolución que el uso de nuevas tecnologías está suponiendo en la creación de nuevos espacios de comunicación. Al mismo tiempo, el prototipo resultante de la modificación de este elemento de juego infantil, bautizado con el nombre de Vídeo Balancín es el resultado de nuestras investigaciones en el campo científico de estudio de los nuevos dispositivos de comunicación entre el ser humano y el ordenador ${ }^{12}$. Con todo ello hemos creado una 
referencia cultural basada en elementos tradicionales y una propuesta de actualización de uno de estos elementos.

Zona de Recreo establece un nuevo sistema de juego interactivo multiusuario al unir la condición física y digital de juego en grupo. Para poder jugar resulta necesaria la colaboración entre los usuarios (máximo cuatro) con la finalidad de mover físicamente la estructura, con esta estrategia el dispositivo favorece la comunicación entre los participantes y ayuda al establecimiento de las relaciones personales presenciales, en contraposición a los juegos multiusuario del momento, en los que la colaboración se realizaba únicamente al campo virtual. En este sentido hemos de recordar que la Nintendo Wii, un ejemplo claro de colaboración físico-digital por medio de los videojuegos, apareció en el año $2006^{13}$ y supuso toda una revolución en el ámbito de los videojuegos con más de cien millones de unidades vendidas en todo el mundo ${ }^{14}$.

El videojuego desarrollado específicamente para Zona de Recreo consiste en un espacio interactivo tridimensional que invita a los jugadores a navegar por un mundo sintético construido con claras referencias gráficas a la película $\operatorname{Tron}^{15}$, como representaciones de las zonas virtuales de relación social, donde el jugador debe ir encontrando determinadas puertas de acceso a los mundos capturados del mundo real, con referencia a los tradicionales parques y zonas de relación social en el espacio público urbano.

Fig. 5 Imagen de Zona de Recreo, Kiasma Art Museum, ISEA 04 Helsinki

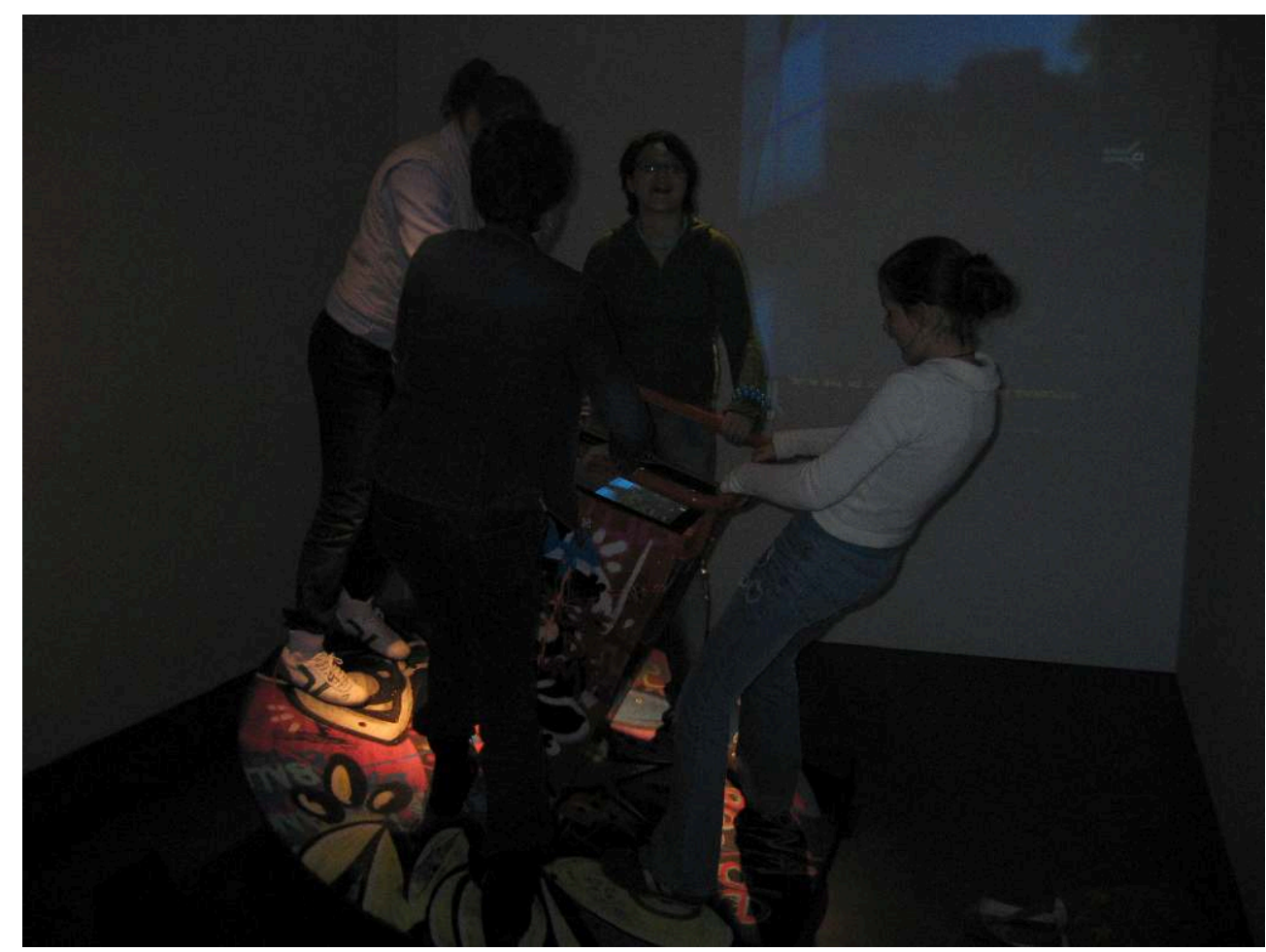

Clara Boj \& Diego Diaz, 2004

En el mundo capturado los usuarios son invitados a viajar por doce parques diferentes de la ciudad de Valencia. Estos parques introducen a los usuarios en una experiencia de vídeo inmersivo $360^{\circ}$ donde pueden acceder a las grabaciones de los parques realizadas para esta investigación al ir variando la inclinación de la estructura física a la que están 
subidos. Nuestra vista pivota alrededor de un ficticio eje central permitiéndonos ir descubriendo áreas específicas e ir completando una visión global del panorama.

Fig. 6 Imagen de Zona de Recreo, Over the Game, Espacio Iniciarte, Sevilla

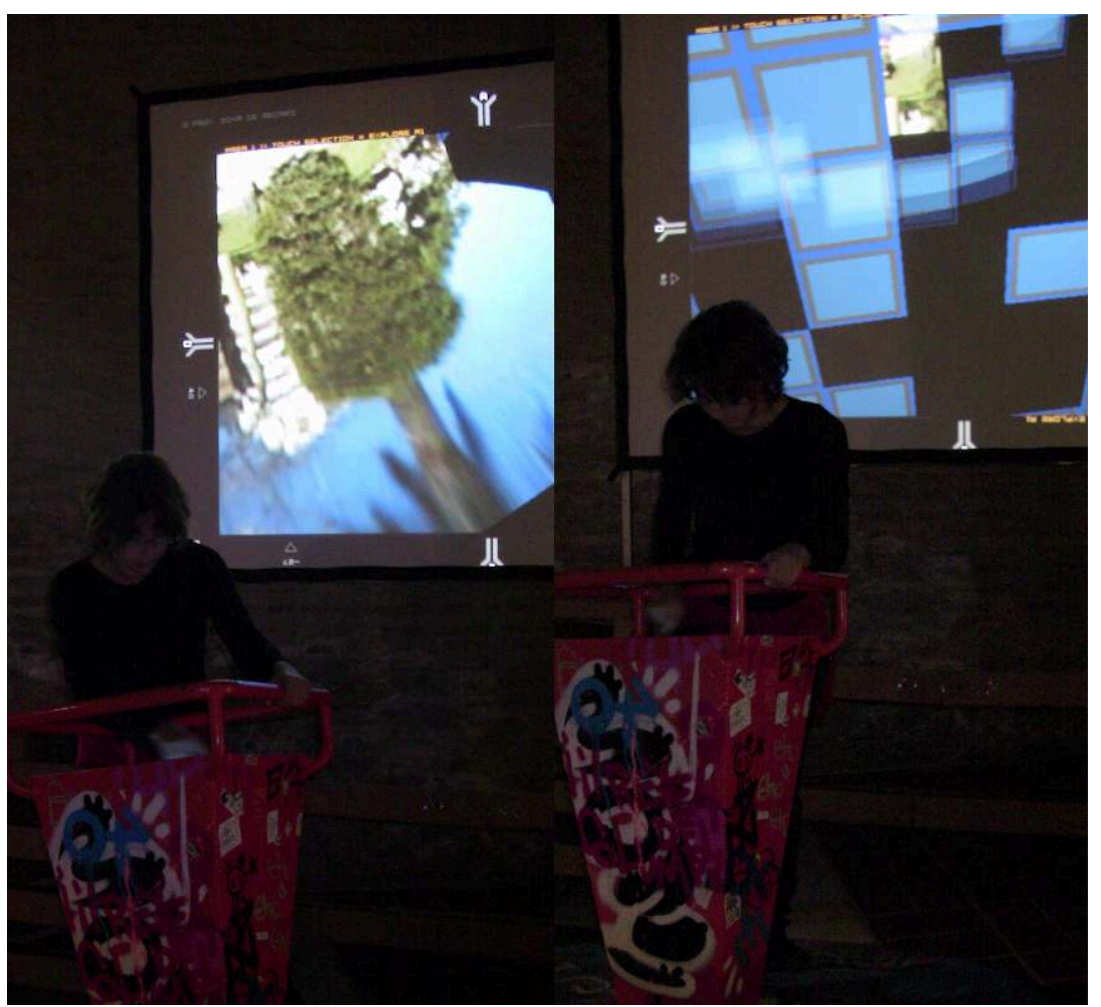

Clara Boj \& Diego Diaz, 2009

\subsection{Hybrid Playground}

El proyecto Hybrid Playground ${ }^{16}$ trata de abordar una transformación integral de los parques infantiles, siguiendo con la investigación iniciada en el anterior proyecto Zona de Recreo, en este caso no planteamos realizar ninguna modificación o transformación física a los elementos del parque. Nuestro objetivo es transformar el parque infantil temporalmente en un escenario para los videojuegos físicos y colaborativos, con el fin de estudiar cómo estos mecanismos de juego pueden ayudar a extender el rango de edades de uso de los parques infantiles y también fomentar el ejercicio físico al aire libre.

Para llevar a cabo esta investigación diseñamos una red de sensores inalámbricos interconectados de fácil acoplamiento a los elementos existentes en el parque que registran los movimientos y acciones de los niños en balancines, columpios y toboganes. Los sensores se acoplan temporalmente a cualquier juego existente y nos permiten obtener datos relativos a su uso como el ángulo de inclinación en los columpios, la velocidad al deslizarse por el tobogán, el balanceo, etc..

El conjunto de dispositivos que conforman Hybrid Playground han sido diseñados con la intención de que se adapten a cualquier elemento de parque urbano existente, estos no sufren ninguna alteración que transforme su diseño actual y no suponen ningún 
peligro para los niños. Son dispositivos autónomos que pueden ser utilizados tanto en instalaciones al aire libre como en espacios interiores.

Estos datos son registrados y enviados a las terminales móviles de juego (PDA) que llevan los jugadores. A partir de estos datos y mientras los niños juegan en el parque se activan distintas estrategias de juego interactivo. Los jugadores deben superar pruebas, encontrar elementos escondidos, superar niveles, perseguir a otros jugadores, etc. siguiendo la narrativa propuesta por la PDA y mediante la utilización de los elementos de juego infantil del parque. De esta manera los niños juegan a un videojuego mientras utilizan los elementos del parque tal y como siempre lo hacen, es decir, tirándose por el tobogán, columpiándose, corriendo, etc.

Fig. 7 Imagen de Hybrid Playground, Murcia

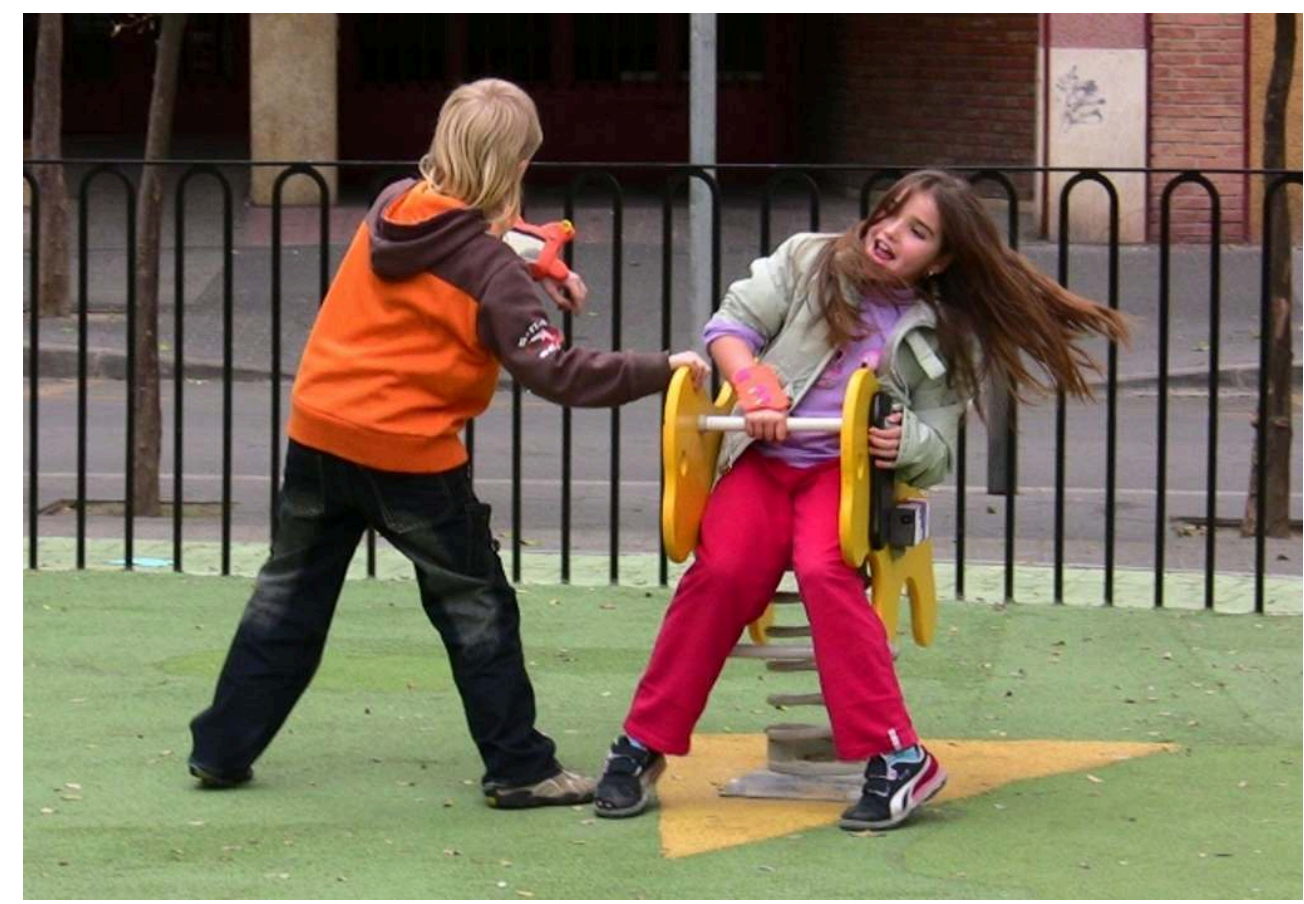

Clara Boj \& Diego Díaz, 2009.

Con esta investigación hemos diseñado un sistema tecnológico que transforma los parques infantiles en espacios híbridos de juego, donde al sensorizar los dispositivos físicos tradicionales de juego los transformamos en interfaces de control de videojuegos. Este sistema interactivo para parque urbano infantil permite la puesta en práctica de experiencias lúdicas que combinan aspectos propios de los juegos de ordenador con dinámicas de comunicación y movimientos físicos al aire libre. Mientras que otras investigaciones en esta misma área centran su atención en superar las dificultades técnicas propias de la integración permanente de sistemas digitales en los elementos de los parques, nuestro proyecto está especialmente dirigido a configurar una nueva comprensión del espacio público, utilizando elementos y paradigmas de comportamiento específicos de la ciudad tangible combinados con recursos y estrategias propias de los videojuegos y sus imaginarios. 
Fig. 8 Detalle de un videojuego desarrollado para Hybrid Playground

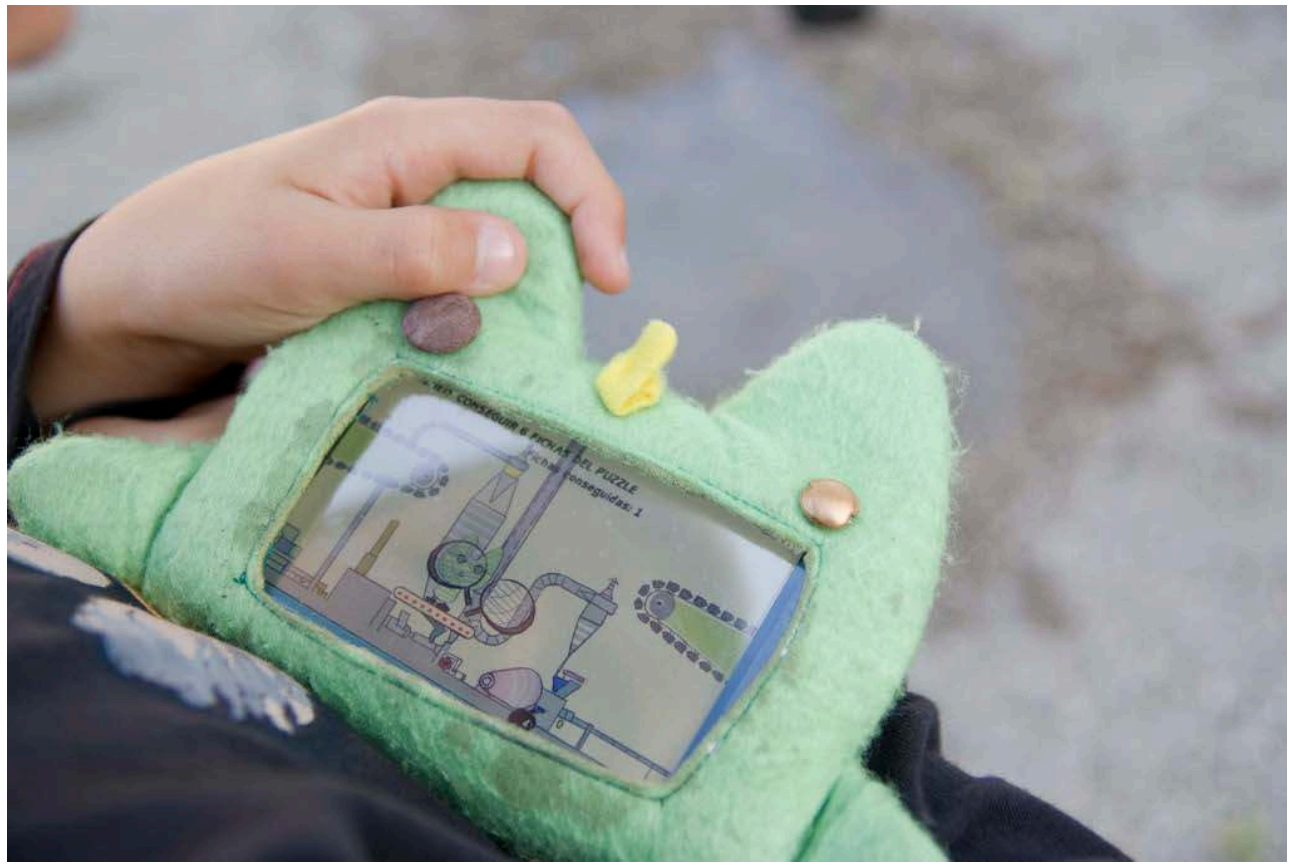

Clara Boj \& Diego Diaz, 2008.

Desde el inicio, Hybrid Playground ha pasado por diferentes fases de experimentación y desarrollo en las que hemos tenido la oportunidad de jugar con niños y niñas de diferentes países y edades. A partir de estos talleres y sesiones de juego hemos desarrollado diferentes prototipos que incorporan mejoras técnicas y estratégicas relativas a las dinámicas del juego. En el año 2012 retomamos el proyecto para adaptarlo a las tecnologías del momento, rediseñando integralmente la carcasa de los sensores, las placas de electrónica y conectando el sistema a teléfonos móviles inteligentes Android y IPhone ${ }^{17}$, además realizamos algunos estudios del uso del sistema para personas mayores en parques de ejercicio al aire libre ${ }^{18}$. 
Fig. 9 Imagen de Hybrid Playground, Gijón

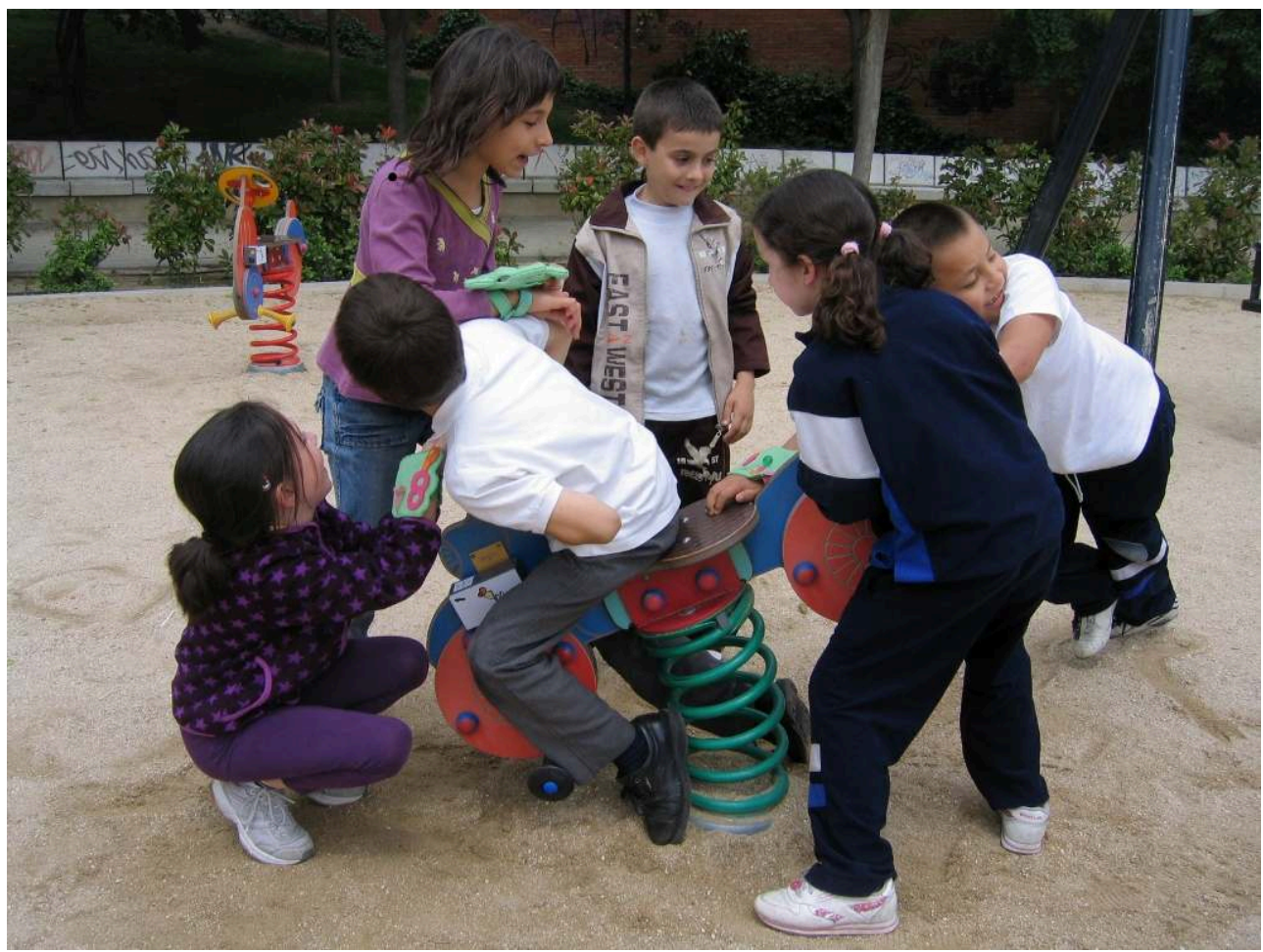

Clara Boj \& Diego Diaz, 2008 posibilidad de jugar a un en cualquier lugar. Sin embargo, vincular el desarrollo de estas actividades a espacios y elementos concretos de la ciudad e incorporarlos activamente en la acción enriquece la percepción del espacio y el cuerpo físicos, a la vez que ayuda a establecer nuevos vínculos con la ciudad y fomenta las relaciones interpersonales y el ejercicio físico.

\section{Ciudad de datos}

31 La computación ubicua ${ }^{19}$, unida al desarrollo de las redes de comunicación que se han extendido de manera intensiva por los territorios urbanos añaden una nueva característica a nuestras ciudades. Estas redes, que responden a diversas configuraciones tecnológicas, tanto cableadas como inalámbricas, bien sea por satélite, radio o wi-fi, posibilitan la conexión continua y permanente entre zonas geográficamente alejadas llamadas nodos.

Las redes de datos configuran un territorio físico pero imperceptible al ojo humano que inunda nuestras ciudades y se establece como capas de información superpuestas a la capa física urbana. Redes de telefonía, redes inalámbricas de internet, redes GPS por satélite, redes bluetooth, etc. todos estos canales de comunicación transmiten diariamente millones de paquetes de información que nos rodean de manera invisible. La ciudad de datos es una realidad que transforma el paisaje urbano que se entiende ahora como un espacio híbrido entre lo físico y lo digital. Este paisaje, configurado por los elementos del urbanismo : edificios, calles, plazas que se mezclan con los emails, los 
SMS, etc. produce cambios en la esfera pública y en la manera en que los ciudadanos se relacionan en ella. de realidad aumentada, el flujo de información que intercambian los usuarios en una red wifi. Estos usuarios pueden ver objetos virtuales de colores que representan los datos digitales que en ese momento se encuentren volando por el espacio físico. Estos objetos tienen formas, tamaños y colores diferentes en relación a las características de la información que circula por la red.

Fig. 10 Imagen de Free Network Visible Network, Kioto

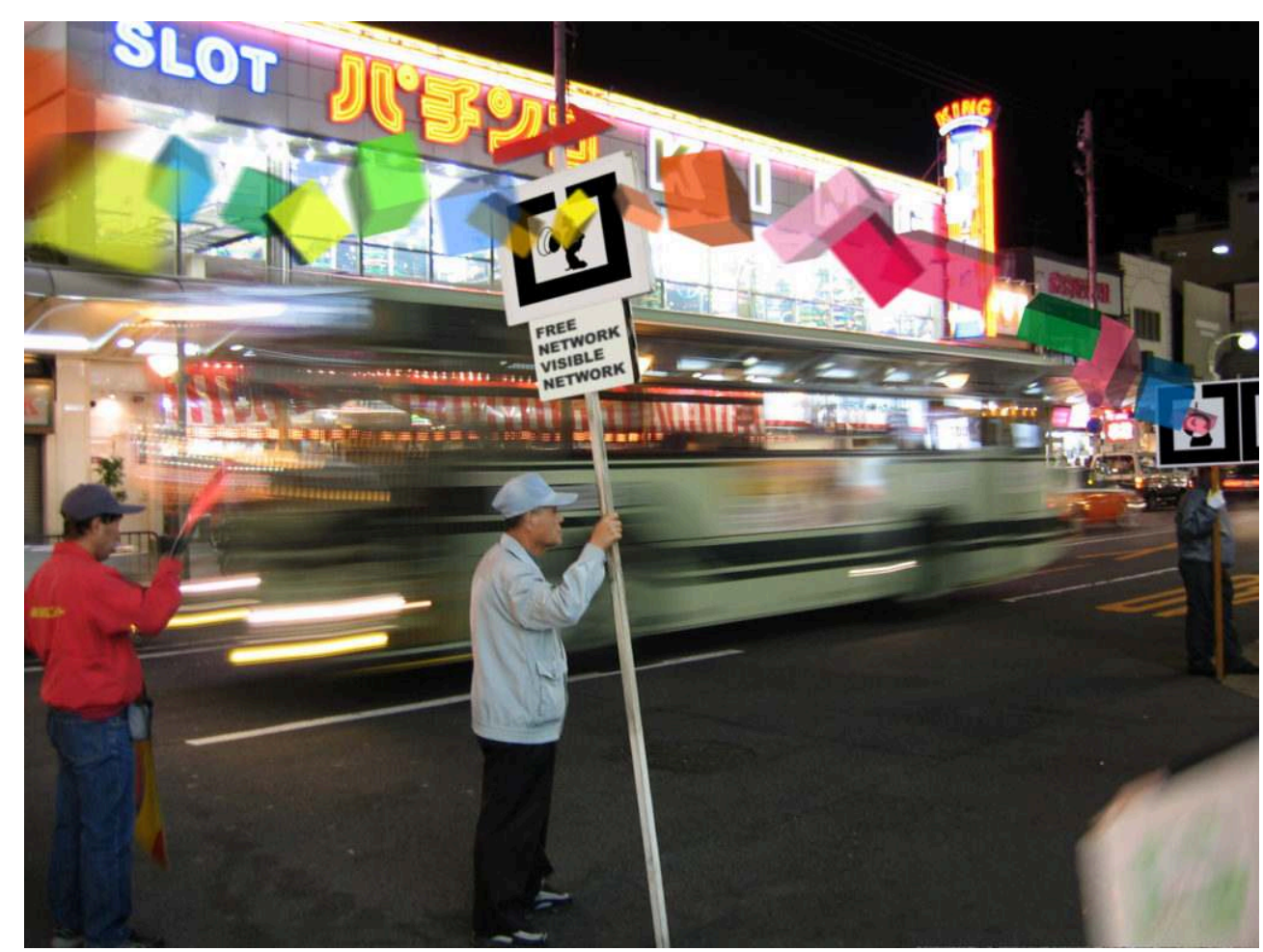

Clara Boj \& Diego Díaz, 2004.

En los últimos treinta años la información digital ha inundado el mundo en el que vivimos. No importa donde estemos, incluso si no somos capaces de verlo, nos podemos imaginar cómo estamos rodeados de datos. Estos datos, a pesar de su naturaleza digital, 
están comunicando a personas, están llenos de información que contiene conocimiento, ideas, sentimientos y emociones. El espacio de las redes digitales también es el espacio de los significados invisibles que representan relaciones entre personas y un intercambio dinámico de conocimiento. Pero desafortunadamente no todo el mundo puede acceder a esta información a causa de limitaciones técnicas, económicas o incluso políticas. La mayor parte de las redes digitales están restringidas y a menudo la información es filtrada en relación a criterios económicos o ideológicos que afectan al receptor final.

Con la representación metafórica de estos significados invisibles, este proyecto quiere actuar en el espacio urbano como manera de crear nuevas estrategias en el espacio público y reclamar, por medio de acciones artísticas, el derecho de los ciudadanos de acceder y controlar el espacio digital de comunicación para crear Redes Libres que ofrezcan acceso a la información abierta y libre a todo el mundo.

Por Red Libre entendemos cualquier ordenador que permite tránsito local abierto. Por tránsito nos referimos a la información que fluye a través de la red. Una Red Libre se define por lo que los usuarios pueden hacer en ella, más que por la tecnología con la que se construye. Sin embargo este proyecto se centra en las redes inalámbricas ya que son la manera más económica de establecer una red que pueda ser gestionada por sus propios usuarios.

Las redes inalámbricas libres no son posibles sin la participación de la gente. Están creadas con la colaboración de los usuarios que actúan como puentes de comunicación entre nodos. Uno de los principales problemas de estas redes es la limitación en cuanto a la necesidad de establecer una distancia mínima entre nodos. Nuestro proyecto quiere proyectar la ilusión de un mundo conectado a partir de la interconexión de miles de Redes Libres.

El primer paso del proyecto es indicar la presencia de un nodo Wi-Fi. Colocando una marca que señaliza donde hay una red libre, cada nodo de esa red se convierte en un símbolo urbano fácilmente identificable. Esto se basa en la idea de "warchalking" ${ }^{20}$, un término desarrollado por Matt Jones que se refiere al acto en el cual la gente camina por la ciudad en busca de redes Wi-Fi y deja un simple dibujo con tiza para que otros puedan encontrarlos sin dificultad. De esta manera la gente puede encontrar puntos de acceso a la red que le permiten conectarse a la red e incluso a internet en un espacio público, sin tener que conocer la clave, romper las contraseñas o pagar una tasa.

41 El movimiento "warchalking" utiliza algunos símbolos estándar derivados del viejo lenguaje "hobo". En nuestro proyecto, a diferencia de estos símbolos, se puede utilizar cualquier mensaje que se coloque dentro de un marco pre-diseñado. De este modo todas las marcas son directamente una reivindicación visible de las redes libres en el espacio público. 
Fig. 11 Imagen de Free Network Visible Network, Valencia

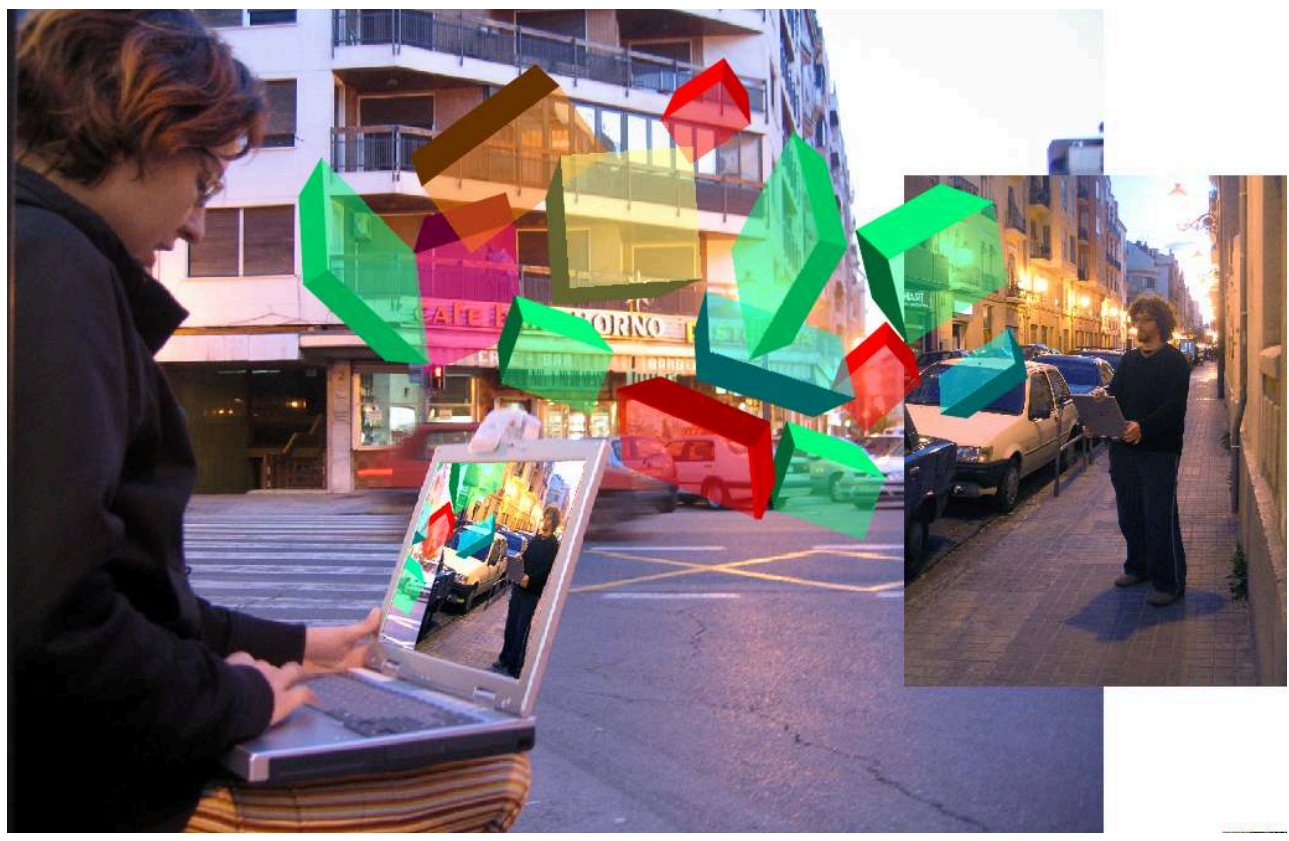

Clara Boj \& Diego Diaz, 2004

42 Red Libre Red Visible tiene lugar al mismo tiempo en el espacio público físico y el digital, estableciendo relaciones directas entre mensajes visuales físicamente colocados en las calles de la ciudad e información digital virtual que flota en el aire ${ }^{21}$. Los mensajes reales y la información virtual están conectados por el elemento principal de este proyecto: el software Red Visible que convierte los datos capturados en objetos virtuales y los superpone en tiempo real al espacio real. Este software está basado principalmente en la tecnología de realidad aumentada usando MXRToolKit, una herramienta open source, desarrollada en el Mixed Reality Lab de la National University de Singapur, combinado con CarnivorePE, un proyecto de software-art del Radical Software Group que escucha el tráfico de internet de una red específica. ${ }^{22} \mathrm{La}$ unión entre estas tecnologías nos ha permitido desarrollar un sistema para visualizar por medio de realidad aumentada la representación metafórica de los datos que continuamente nos rodean.

\subsection{Observatorio}

43 Como sucede habitualmente cuando una nueva tecnología irrumpe en el espacio común, los escenarios utópicos que en una primera etapa auguran transformaciones liberadoras se vuelven mucho más complejos, en cuanto estas tecnologías se ven rodeadas por agentes políticos, económicos y sociales que luchan por monopolizar el discurso de sus aplicaciones.

Las "utopías sin hilo" de la tecnología Wi-Fi y su manifestación en redes ciudadanas defendieron que el acceso a las infraestructuras inalámbricas de datos se debería entender como una extensión del espacio público y, por lo tanto, debería ser de acceso libre y de gestión comunitaria. En el escenario actual, proyectos con una gran base social como la red ciudadana Guifi.net ${ }^{23}$ en Cataluña mantienen vivo el ideal de una 
infraestructura compartida. Pero la superposición de otros actores con intereses contrapuestos han introducido muchas más tensiones en el espacio híbrido.

Instituciones públicas como la Comisión del Mercado de Telecomunicaciones (CMT) han actuado activamente, en nombre de la regulación del mercado, en contra de las iniciativas municipales de ayuntamientos que pretendían ofrecer acceso libre y gratuito a internet desde sus calles. Los operadores comerciales han desincentivado a los usuarios de que abran su conexión para que esta pueda ser utilizada por terceros ; en buena parte este mensaje ha calado apelando al "miedo e incertidumbre" de lo que podría pasar si dejamos nuestra conexión en manos de extraños. En sus intenciones, es difícil no encontrar además el interés en explotar comercialmente tecnologías alternativas mucho menos horizontales, como las telefonías $3 G$ y $4 G$, que escalan con mayor dificultad a usuarios múltiples. El modelo de las redes ciudadanas ha sido incluso adoptado por compañías que pretendían monetizarlo y hacerlo rentable. El caso más conocido es $\mathrm{FON}^{24}$, fundado por el conocido emprendedor Martin Varsavsky, que pretendió, con éxito discutible, fomentar que los usuarios abriesen parte de su conexión a terceros a cambio de una pequeña retribución compartida con la empresa.

Fig. 12 Imagen de la visualización proporcionada por Observatorio, Campos invisibles, Ars Santa Mónica, Barcelona

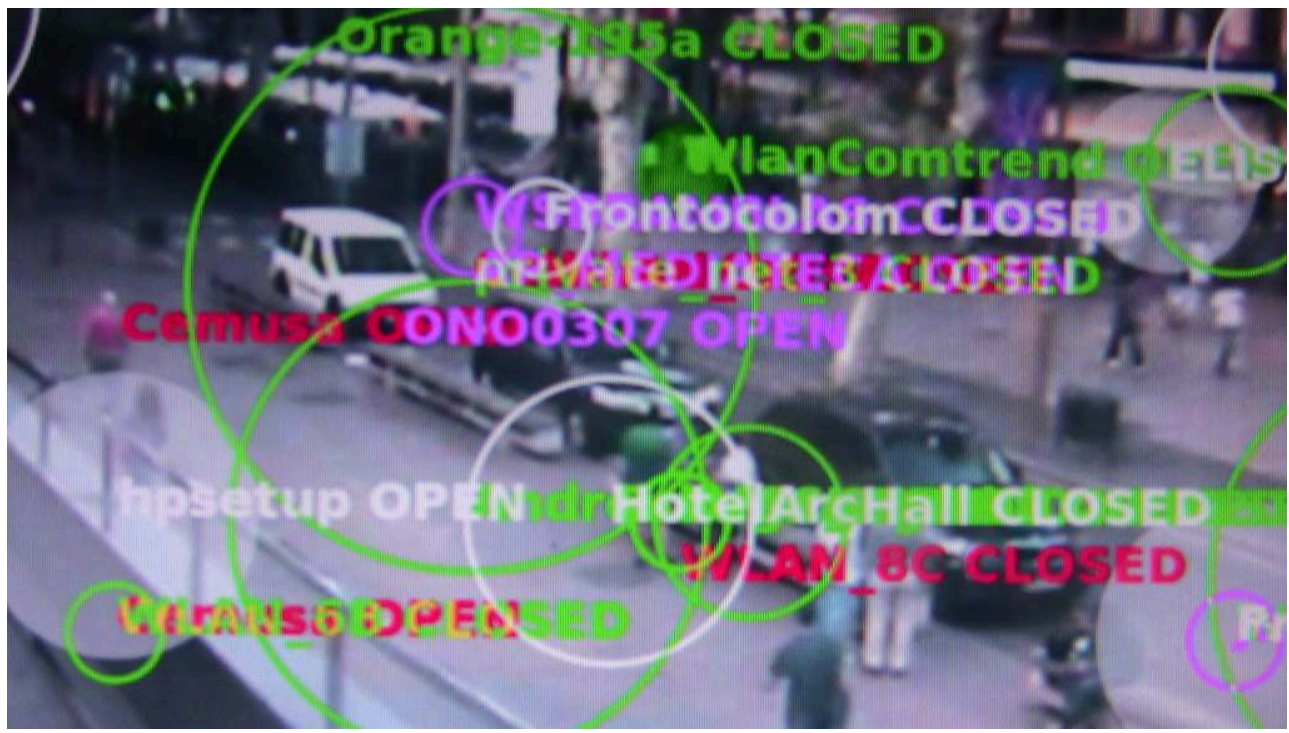

Clara Boj \& Diego Díaz, 2011.

En este contexto de desarrollo del espectro radioeléctrico desarrollamos la investigación observatorio con la intención de realizar un mapeo del número y las características de las redes inalámbricas que en cada momento se encuentren activas y visualizarlas en una ubicación predictiva por medio de tecnología de realidad aumentada. Observatorio nos habla sobre la compleja topología tecnológica y política de la frecuencia radioeléctrica de 2.4 Gigaherzios en las ciudades occidentales al final de la primera década del siglo XXI. El proyecto plantea que el paisaje de una ciudad contemporánea no puede incluir sólo los contornos de lo tangible, sino que debería incorporar modos de representación de la actividad social y el tráfico en sistemas que no se perciben a primera vista.

Este proyecto se concreta en un dispositivo que es literalmente, un telescopio de realidad aumentada; observando a través de su visor, podemos ver algo más que el 
paisaje de la ciudad. Junto a la cámara de video, una antena direccional Wi-Fi de alta potencia detecta las redes inalámbricas que hay activas en la dirección hacia la que estamos mirando en un radio de varios kilómetros de distancia. Al girar el telescopio, recorremos con la mirada el espacio hertziano y nos topamos con decenas de señales que emanan de domicilios, empresas, cafés, hoteles, restaurantes. En una gran mayoría estarán cerradas y aunque recibimos sus ondas no podremos acceder a internet si carecemos de su contraseña. Cuando las redes están abiertas, el dispositivo se conecta a ellas y el Observatorio pasa a convertirse en un sistema de transmisión que envía la información de las redes encontradas y las imágenes capturadas por la cámara a la sala de exposiciones, donde esta información es mostrada en una instalación espacial de grandes dimensiones.

Observatorio se presentó por primera vez en junio de 2008 en la ciudad de Gijón, en el contexto de la exposición Banquete, Nodos y Redes. Se instaló un dispositivo en la Torre de la Universidad Laboral situada en una zona periférica desde la que se ve claramente todo el casco urbano y muy próxima a la LABoral Centro de Arte y Creación Industrial, con el que estaba conectada y estuvo en funcionamiento continuado durante cinco meses.

Fig. 13 Imagen de Observatorio, Banquete, nodos y redes

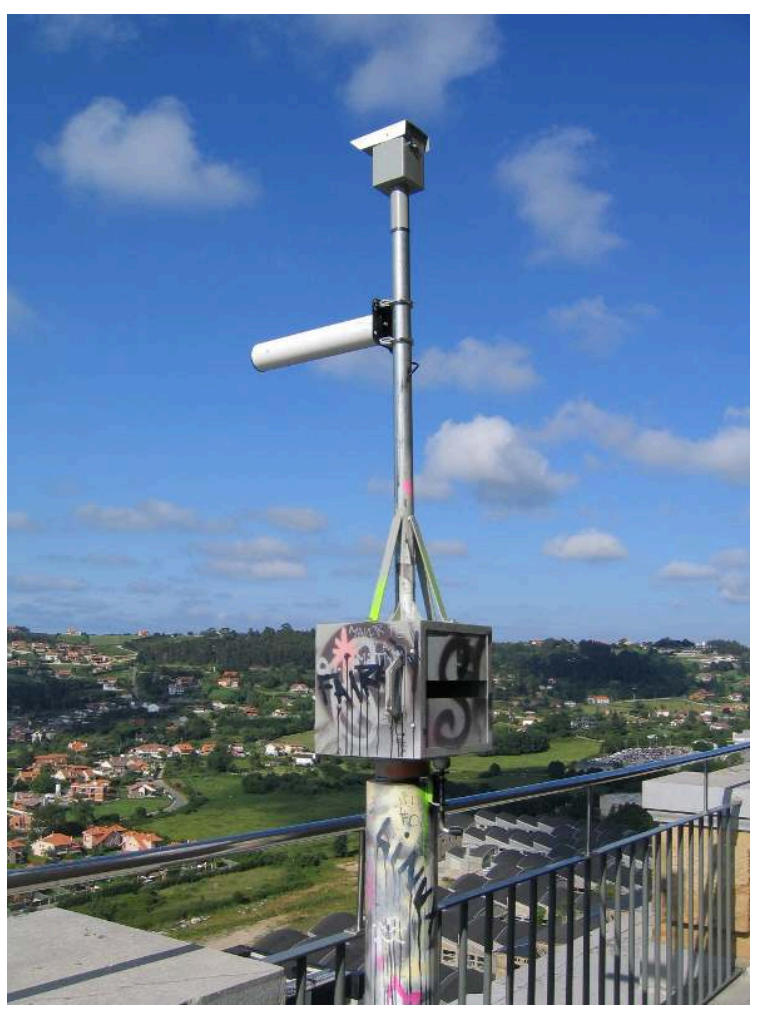

La Laboral Centro de Arte, 2008.

De marzo a junio de 2009, Observatorio se instaló en la ciudad de Karlsruhe (Alemania) conectado con el museo ZMK. En esta ocasión, el emplazamiento elegido fue el Turmberg, una colina que ofrece una excelente panorámica de la ciudad y sus suburbios. Con motivo de la exposición Gateways, Art and Networked Culture, se instaló en el Kumu Art Museum, Tallin, Estonia en el año 2011. 
Fig. 14 Imagen de Observatorio, Gateways, Kumu Art Museum, Tallin

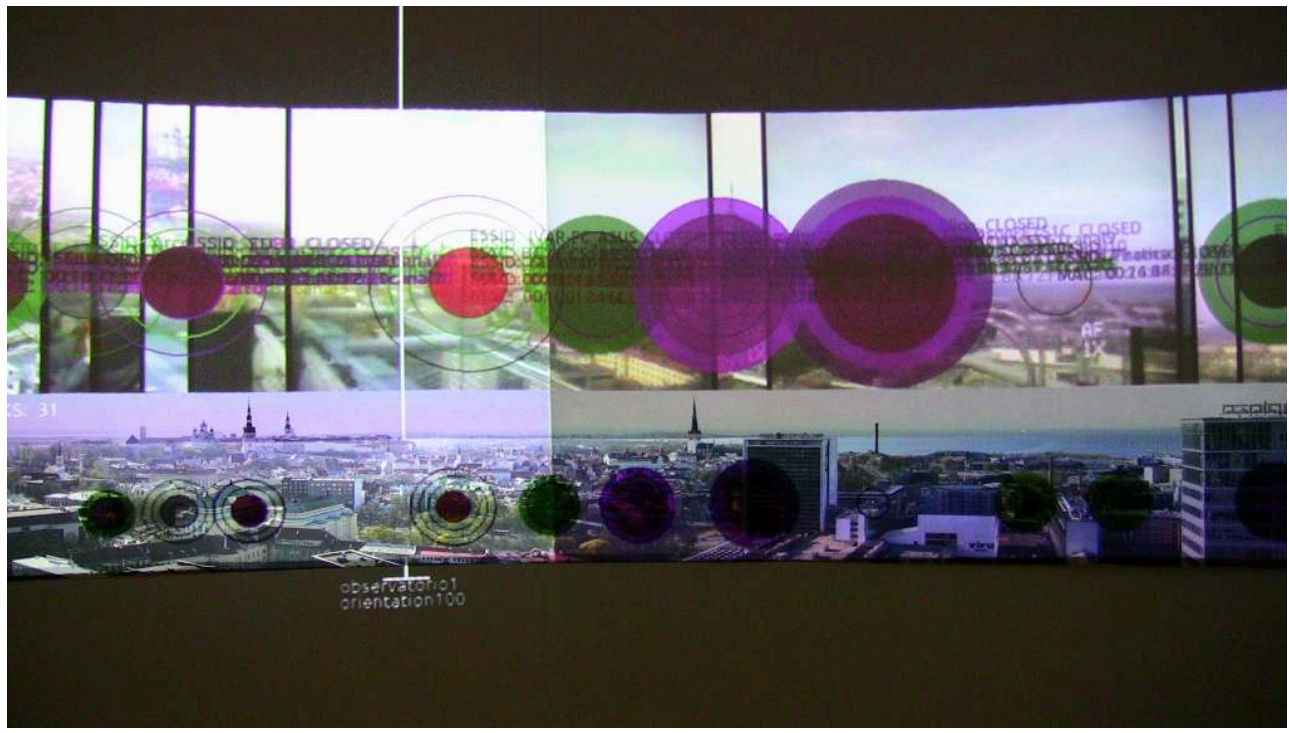

Clara Boj \& Diego Díaz, 2011.

En Valencia el proyecto se ha ampliado y extendido a tres puntos distintos de la ciudad, todos ellos torres emblemáticas que constituyen los principales referentes visuales del casco histórico así como las atalayas a las que cualquier visitante ocasional acude para disfrutar del paisaje y conocer el territorio y sus límites. El Miguelete, torre campanario de la catedral de Valencia y las Torres de Quart y Serranos, puertas de acceso a la ciudad amurallada medieval, se han transformado durante dos meses en puestos de observación y registro de las redes inalámbricas ayudándonos a componer un panorama mucho más completo, un recorrido en 360 grados de la ciudad desde su centro.

Fig. 15 Imagen de Observatorio, Torres de Serrano, Valencia

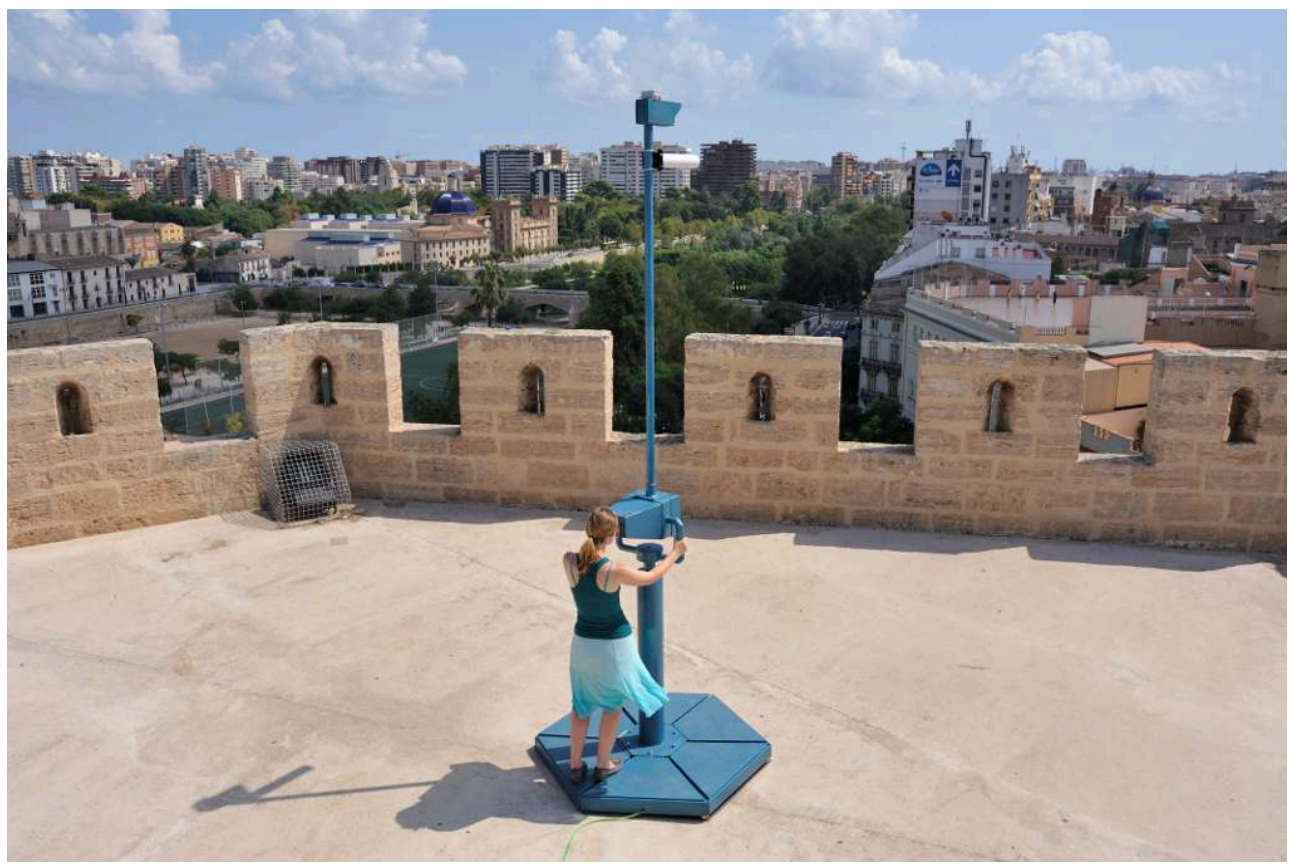

Clara Boj \& Diego Díaz, 2009. 
Los tres dispositivos observatorios se conectaron con la Sala Parpalló y enviaron información de su estatus y de los nuevos descubrimientos que turistas y visitantes ocasionales han provocado al mirar el paisaje a través de ellos. De este modo los gestos de cada visitante se suman a los anteriores y confluyen en la sala expositiva incrementando el registro de redes y activando la actualización continua del archivo y su visualización.

Fig. 16 Imagen de Observatorio, Sala de exposiciones Parpalló, Valencia

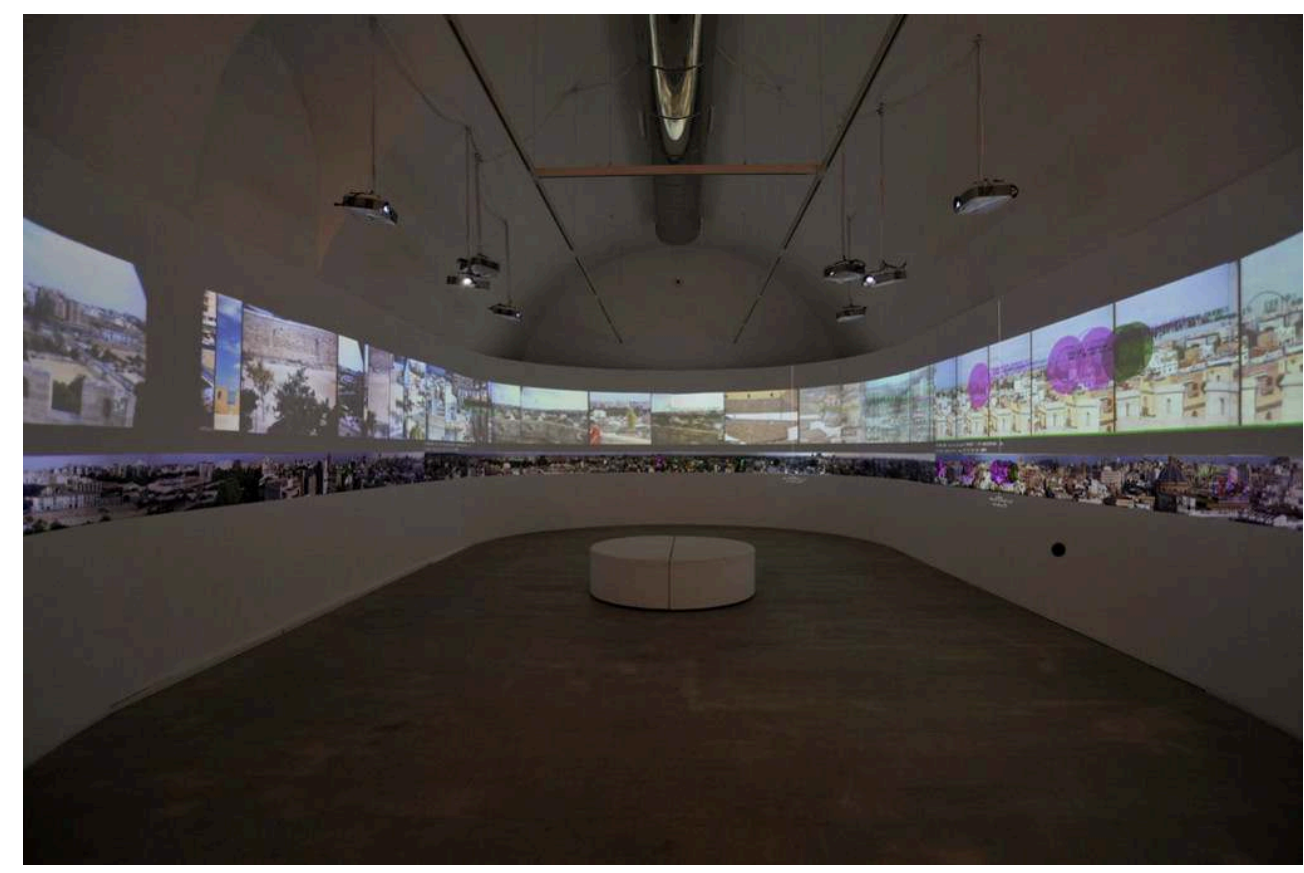

Clara Boj \& Diego Díaz, 2009.

Las atalayas que el proyecto propone sobre Valencia no son tres lugares cualquiera : El Miguelete, las Torres de Serrano y las Torres de Quart, tres puntos significados históricamente que son para el turismo que visita la ciudad los tres lugares obvios desde los que contemplar en altura la capital levantina. La complicidad con el visitante se refuerza con la interfaz del dispositivo que remite claramente a los telescopios turísticos de monedas que durante años han ocupado los puntos de observación panorámica de vistas en la geografía española.

Desde los tres observatorios, las imágenes de video se mandan hasta la sala de exposiciones, en la que las imágenes de la ciudad, enviadas desde los observatorios, muestran el horizonte en tiempo real de manera interrumpida, en función de la disponibilidad de esta conexión, y de manera fraccionada. Como el paisaje hertziano, el comportamiento de los observatorios es inestable, transitorio y está en permanente estado de flujo.

\section{Conclusiones}

En esta publicación hemos presentado las dos líneas esenciales de investigación en nuestra producción artística realizada desde el año 2003 hasta el 2008. Entendiendo la ciudad híbrida como una ciudad sensible y reactiva, con los proyectos A Central Axis 
(2003), Zona de Recreo (2003) y Hybrid Playground (2008), proponemos acercarnos a la percepción de la ciudad desde el juego y la activación lúdica de los espacios públicos. Por otro lado, desde una aproximación a la ciudad de datos, con los proyectos Red Libre Red Visible (2004) y Observatorio (2008), realizamos un acercamiento a la visualización, relacionada con la tradición pictórica del paisaje, del espectro radioeléctrico y su influencia social y política en la construcción del espacio público digital.

\section{NOTAS}

1. Branden ноокшау, Interface, Cambridge, MA, The Mit Press, 2014.

2. Steven JoHnson, Interface Culture: How New Technology Transforms the Way We Create and Communicate, San Francisco, Harper, 1997.

3. Ida SUSSER, The Castells Reader on Cities and Social Theory, Malden, MA, Blackwell, 2002. p. 382

4. Greg P. GRIFFIN, « The City as Interface, by Martijn de Waal », Urban Geography, Volume 36, Issue 4 (2015), p. 625-627.

5. Martijn DE WAAL, The City as Interface: How Digital Media Are Changing the City, Rotterdam, Nai010 Publishers, 2014.

6. Mark WEISER, « Hot Topics-Ubiquitous Computing », Computer 26 (10), (1993), p. 71-72.

7. Kristrún GUNNARSDótTIR, y Michael ARRIBAS-AYLLON (2012), «DISCUSSION PAPER: Ambient Intelligence: A Narrative in Search of Users » [on-line], Lancaster University and SocSI, Cardiff University, Cesagen, [disponible el 19/05/2020] <URL: https://www.researchgate.net/ publication/

281236379_DISCUSSION_PAPER_Ambient_intelligence_a_narrative_in_search_of_users>

8. Clara BoJ y Diego DÍAZ (2003a), «A Central Axis - > CLARA BOJ + DIEGO DÍAZ » [on-line], Valencia, Lalab [disponible el 19/05/2020] URL: http://www.lalalab.org/a-central-axis/

9. Oliver BIMBER, y Ramesh RASKAR, Spatial Augmented Reality: Merging Real and Virtual Worlds. Spatial Augmented Reality: Merging Real and Virtual Worlds, New York, ImprintA K Peters/CRC Press, 2005.

10. Clara BoJ, Diego DíAZ y Adrian David CHEOK, Mix Zonas Projects, Singapore, National University of Singapore, 2003.

11. Clara BOJ y Diego DíAZ (2003b), «Zona de Recreo - > CLARA BOJ + DIEGO DÍAZ » [on-line], Valencia, Lalab [disponible el 19/05/2020] URL : http://www.lalalab.org/zona-de-recreo/

12. Thomas HEWETt, Ronald BAECKER, Stuart CARD, Tom CAREY, Jean GASEN, Marilyn MANTEI, Gary PERLMAN, Gary STRONG, y William VERPLANK, «ACM SIGCHI Curricula for Human-Computer Interaction », ACM SIGCHI Curricula for Human-Computer Interaction (Enero de 1992).

13. Gadget GURU (2006), « FOXNews.Com - Nintendo to Sell Wii Console in November - Technology News | News On Technology»[on-line], Associated Press [disponible el 19/05/2020] <URL: https://www.foxnews.com/wires/2006Sep14/0,4670,NintendoWii,00.html>

14. Matt LIEBL (2013), «Wii Lifetime Sales Surpass 100 Million Units | GameZone » [on-line], Gamezone [disponible el 19/05/2020] <URL: https://www.gamezone.com/news/wii-lifetimesales-surpass-100-million-units/>

15. Steven LISBERGER (1982), «TRON » [on-line], IMDb [disponible el 19/05/2020] <URL: https:// www.imdb.com/title/tt0084827/> 
16. Clara BOJ y Diego DÍAZ (2008), « Hybrid Playground - > CLARA BOJ + DIEGO DÍAZ » [on-line], Valencia, Lalab [disponible el 19/05/2020] URL: http://www.lalalab.org/hybrid-playground/ 17. Diego díAz, Clara Boj y Cristina PORTALÉs, 2016. «Hybridplay: A New Technology to Foster Outdoors Physical Activity, Verbal Communication and Teamwork », Sensors (Switzerland) 16 (4), (2016), 586.

18. Clara BOJ, Diego díAz, Cristina PORTALÉS y Sergio CASAS, «Video Games and Outdoor Physical Activity for the Elderly: Applications of the HybridPLAY Technology ", Applied Sciences (2018) 8, 1912.

19. Mark WEISER, Op. cit.

20. Roberto BAtTiti, Renato lo Cigno, Mikalai SABEL, Fredrik oraVA, y Björn PEHRSON. 2005. "Wireless LANs: From Warchalking to Open Access Networks ». Mobile Networks and Applications, volumen 10 (2005), p. 275-287.

21. Clara BOJ, Diego DÍAZ, A.D. СНEOK, K. XU, Y W. LIU, « Free Networks Visible Networks », Proceedings of the 2005 International Conference on Active Media Technology, AMT 2005, vol. 2005.

22. RADICAL SOFTWARE GROUP (2001), « Carnivore » [on-line] [disponible el 19/05/2020] URL: http://r-s-g.org/carnivore/

23. NET GUIFI (2004), «Guifi.Net - Xarxa de Telecomunicacions Oberta, Lliure i Neutral | Guifi.Net » [on-line], GUIFI [disponible el 19/05/2020] <URL : http://guifi.net/>

24. FON (2006), «Fon Is the Global WiFi Network with Millions of Hotspots | Fon » [on-line], FON [disponible el 19/05/2020] <URL: https://fon.com/>

\section{RESÚMENES}

A partir de la aproximación de la concepción de ciudad como una interfaz, en este artículo presentamos algunas investigaciones que hemos realizado durante la primera década de este siglo con el objetivo de analizar las transformaciones que las nuevas tecnologías han impulsado en nuestras ciudades y concretamente en el espacio público. Hemos creído conveniente clasificar las aportaciones bajo las categorías de ciudad sensible - ciudad reactiva, donde presentamos varias experimentaciones que analizan posibles métodos (y sus efectos) de activación lúdica del espacio público y ciudad de datos, en la que reflexionamos sobre la creciente digitalización e hibridación del espacio público e intentamos comunicar visualmente el cambiante espectro radioeléctrico de nuestras ciudades.

Dans la perspective de la conception de la ville comme interface, nous présentons, dans cet article, les recherches que nous avons menées au cours de la première décennie de ce siècle dans le but d'analyser les transformations que les nouvelles technologies ont entraîné dans nos villes et, plus précisément, dans l'espace public. Nous avons jugé opportun de classer les contributions dans les catégories de ville sensible - ville réactive, dans lesquelles nous présentons plusieurs expériences qui nous permettent d'analyser les méthodes possibles (et leurs effets) d'activation ludique de l'espace public et de la ville des données. Nous tâchons de réfléchir à la numérisation et à l'hybridation croissantes de l'espace public et nous essayons de communiquer visuellement l'évolution du spectre radioélectrique de nos villes.

Based on the approach of the conception of the city as an interface, in this article we present some research that we have carried out during the first decade of this century with the aim of 
analyzing the transformations that new technologies have driven in our cities and specifically in the public space. We have considered it convenient to classify the contributions under the categories of sensitive city - reactive city, where we present several experiments that analyse possible methods (and their effects) of playful activation of public space and data city, in which we reflect on the growing digitalization and hybridization of public space and we try to communicate visually the changing radio spectrum of our cities.

\section{ÍNDICE}

Mots-clés: art urbain, médias locatifs, ville ludique, ville hybride

Keywords: urban art, locative media, playful city, hybrid city

Palabras claves: arte urbano, medios locativos, ciudad lúdica, ciudad híbrida

\section{AUTORES}

\section{DIEGO DÍAZ}

Init, Universitat Juame I, Universitat Politécnica de Valencia

CLARA BOJ

Init, Universitat Juame I, Universitat Politécnica de Valencia 